\section{METHODOLOGY FOR THE} UTILIZATION OF WASTE HEAT BY AIR-COOLED COMPRESSORS

LUKAS PACAS

VSB-Technical University of Ostrava, Czech Republic

DOI: 10.17973/MMSJ.2021_10_2021093

\section{lukas.pacas.st@vsb.cz}

Compressed air is still a valid helper in many applications today, where it is necessary, for example, to move work equipment, pistons or it is used for cooling as a cooling medium. The producer of compressed air are air compressors, which need an external source for its production, usually an electric or internal combustion engine. Almost all the energy that is supplied to the compressor is always converted to heat during compression, regardless of the type of compressor. This carries the risk of overheating and therefore the cooling system must be optimally designed. Thus, during the compression of the air, a large part of the electrical energy supplied to the compressor is converted into heat, and only a small part of the supplied energy is in the compressed air. In the case of oil or watercooled compressors, the exchangers can be used directly to obtain energy "for free". In the case of air cooling, a slight energy gain can only be achieved by modifying the exhaust hot air ducts. This energy can be used efficiently to heat water or heat buildings, instead of being uselessly ventilated. Modern compressors are already adapted for the use of waste heat, but most current companies still use older types of compressors that have not been directly adapted for the use of waste heat. In case of interest in obtaining waste heat, the reconstruction of the facility or development is inevitable.

KEYWORDS compressor, air cooling, waste heat, heat utilization, cost savings

\section{INTRODUCTION}

This paper deals with the issue of using waste heat from the operation of screw compressors under given conditions. The issue of waste heat recovery is an increasingly popular topic in conjunction with the ever-increasing pressure to reduce operating costs. This is not the case with the use of waste heat from compressors. While in the last century waste heat from compressors was almost taboo, today it is already a wellestablished standard. Most such systems were created by retrofitting existing compressors. It always depends on the type of compressor. Compressor manufacturers already provide compressors with a built-in heat exchanger. However, such an exchanger is always for the oil circuit only. What if I want to use waste heat from cooling fans? Here is a possibility of a solution. And this is the solution that this paper deals with. On the example from practice, the possibility of using waste heat from a compressor station equipped with 6 screw air-cooled compressors is shown here. This is an obsolete operation where air has been blown out of the radiators to no avail. Two solutions were developed that respected all the above conditions. And most importantly, they led to big savings and the investor showed great interest in these proposals. This proves that the money invested in the reconstruction is not a meaningless cost.

\subsection{Energy balance of the compressor}

In professional publications, it is often believed that almost all the energy supplied to the compressor is dissipated by cooling to the environment in the form of heat. This view is offered if only the so-called shortened energy balance is performed. This balance assumes that only propulsion energy enters the compressor and compressed air and heat exit. However, this idea, which can be used to determine the amount of heat dissipated, is not correct. It forgets the energy that is brought into the process by the intake air and does not respect the transformation of the "workability" of individual energies (in the literature, the term exergy is used for this "workability"). With the right balance, most of the energy supplied by the drive is converted into compressed gas, thus increasing its "workability". The mutual comparison of both balances is for the case of a three-stage compressor is graphically expressed using pie charts (see Fig. 1, 2), where the whole circle (100\%) means the energy supplied by the drive. A more detailed analysis can be found in [Kaminsky 2004].

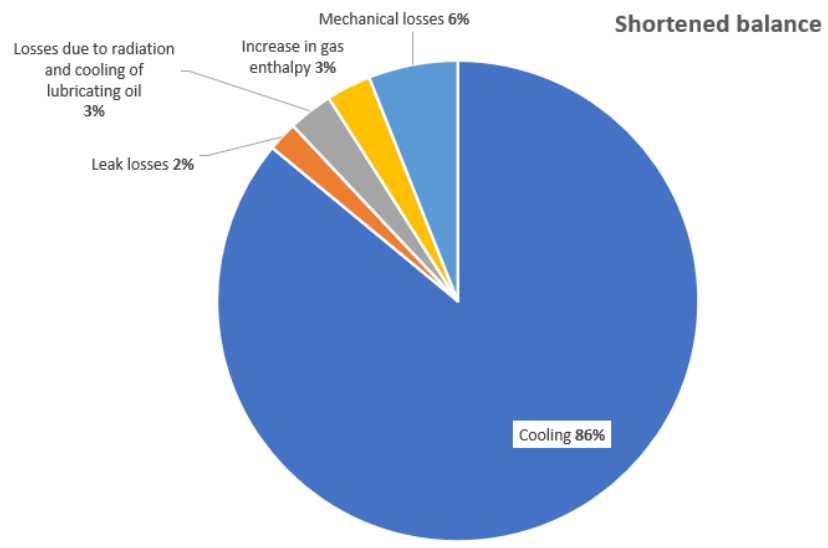

Figure 1. Shortened balance of a three-stage compressor

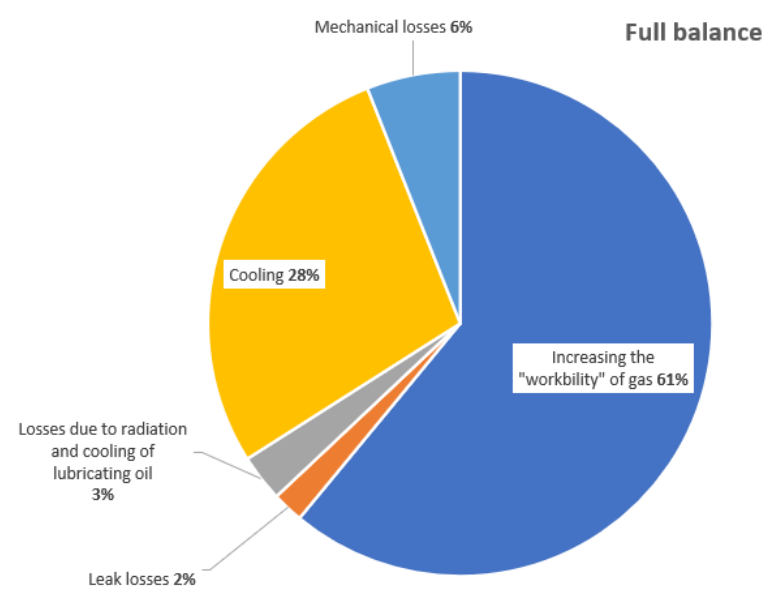

Figure 2. Full balance of a three-stage compressor 


\section{UTILIZATION OF WASTE HEAT IN AIR-COOLED COMPRESSORS}

In this case is usually the most advantageous solution construction of ventilation ducts. It is a simple and inexpensive method that is often used for its fast return on investment. At the time when it is needed, most often in winter, the warm air from the compressor is supplied through ventilation pipes to the rooms where this air is used as a heating medium, such as production halls and warehouses. In summer, when there is no need for heating, warm air from the compressor is led out of the compressor room. This is probably the simplest use of waste heat by air-cooled compressors for hot air heating or tempering of production halls. This method of use requires a compressor, motor and coolers cooled by air, which, when heated, acts as a heat transfer medium. In summer, the heat is released to the surroundings.

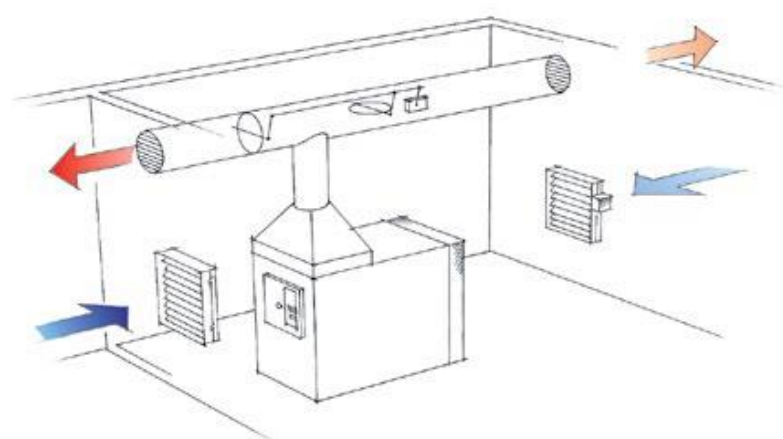

Figure 1. Ventilation pipes

\subsection{Example of using hot air from practice}

As an example of the reconstruction of the existing system, I present a description of the project, which was implemented as part of the expansion of the Model Obaly Nymburk plant. The problem there was insufficient coverage of heat losses in the newly built warehouse part. This company is engaged in the production of paper packaging and part of the production technology is also a corrugating machine, in which a large amount of waste heat is generated. Due to the high noise level, the device is covered with an anti-noise fairing, which is intensively ventilated. The exhaust air temperature reaches 45 ${ }^{\circ} \mathrm{C}$ and was blown by two axial fans above the roof of the hall. This production section was chosen for the treatment for the use of waste heat, as the average heat gain in the cabin, which can be used for heat recovery, is about $100 \mathrm{~kW}$, throughout the shift. Since the place of use of this heat is about 60 meters away and for collisions with various distributions, the passage of the air duct corresponding to the needs is almost impossible, in addition, very expensive. Also the given space for the placement of the device is very small, therefore the use of a classic plate heat exchanger was excluded. Therefore, they decided to use liquid exchangers. This was the first application of this device in industrial conditions. The heat exchanger works on the principle of heat transfer from flowing air into water guided by a polypropylene tube of very small diameter (approx. $3 \mathrm{~mm}$ ), wound into a coil. Warm air is sucked through the winding into the center of the coil, from where it is led to the exhaust through a manifold. The exchangers are assembled as kits from the basic module. In this case, 30 basic modules were used, assembled into 6 sections of 5 modules. All coils of the modules are connected in parallel in sections and the whole set of exchangers it is terminated on the water side with DN 50 sockets. A connection has been established on the air side into a common manifold, which leads to the existing fan intake and is further led to the roof. The water from the heat recovery exchangers is led to three unregulated preheaters, which are sets consisting of an axial fan, two exchangers connected in series in a common frame and pipes with diffusers. This system of waste heat utilization has proven to be a good option for solving energy savings in the conditions of existing production premises with a lack of free space. In addition, this device is simple and easy to maintain.

\section{COMPRESSOR STATION}

The compressor station is used for the production of compressed air for production plants. It is a central compressor station. It is equipped with several large compressors with an extensive pipeline network. The operating air pressure is obtained by operating the compressors. The compressors are located in the compressor station, which are listed e.g. see Tab. 1. The output of the compressor in the table means the amount of compressed air produced per hour. These are screw compressors with oil injection from company Atlas Copco. VSD models (compressors $\mathrm{K} 2$ and $\mathrm{K} 6$ are equipped with a motor frequency converter and can thus operate more economically. They can regulate their performance. All compressors are completely air-cooled.

\begin{tabular}{|c|c|c|c|c|}
\hline Indication & $\begin{array}{c}\text { Electric } \\
\text { motor } \\
\text { power } \\
{[\mathbf{k W}]}\end{array}$ & $\begin{array}{c}\text { Output } \\
{\left[\mathrm{m}^{3} / \mathrm{h}\right]}\end{array}$ & $\begin{array}{c}\text { Modification } \\
{[\mathrm{bar}]}\end{array}$ & $\begin{array}{c}\text { Year of } \\
\text { production }\end{array}$ \\
\hline K1 & 45 & 482 & 7 & 1997 \\
\hline K2 & 160 & $\begin{array}{c}288 \text { to } \\
2172\end{array}$ & 12,5 & 2002 \\
\hline K3 & 160 & 1700 & 7,5 & 2007 \\
\hline K4 & 160 & 1700 & 7,5 & 2007 \\
\hline K5 & 160 & 335 to & 8,5 & 2014 \\
\hline K6 & 160 & 1935 & 8,5 & 2018 \\
\hline
\end{tabular}

Table 1. Compressors in compressor station

Compressors K2-K6 are equipped with air coolers with air flow $Q_{n}=4600 \mathrm{l} / \mathrm{s}=16560 \mathrm{~m}^{3} / \mathrm{h}$, which is given by the manufacturer. For compressor $\mathrm{K} 1$, this flow is equal to $\mathrm{Qn}=$ $1800 \mathrm{l} / \mathrm{s}=6480 \mathrm{~m}^{3} / \mathrm{h}$. For compressors of this output, the temperature of the air flowing from the cooler is around $40{ }^{\circ} \mathrm{C}$ in winter and $46{ }^{\circ} \mathrm{C}$ in summer. However, in extreme situations, this temperature can reach up to $50{ }^{\circ} \mathrm{C}$. Temperatures of $40{ }^{\circ} \mathrm{C}$ were considered for the next calculations.

\section{PROBLEM ANALYSIS}

The heat dissipated by the compressor air coolers is blown out, either outside in summer or inside the compressor room in winter. This heat is therefore considerably unused. In the given conditions, it was possible to use this heat for heating the adjacent workshop, which is located approximately 70 meters from the station. The current heating solution included 9 gas hot air units with considerable gas consumption. More precisely, the annual operating costs of these heating units are CZK 423,969 (EUR 16,500).

Before the calculation, it was necessary to design a manifold that will lead the air from the coolers to a specific location, to the outlet of the compressor station. According to the preliminary design, the values of the air volume flow of the main branch of the pipeline are as follows. 


\begin{tabular}{|c|}
\hline Operation mode \\
\hline 1 \\
\hline 2 \\
\hline 3 \\
\hline 4 \\
\hline 5 \\
\hline
\end{tabular}

Air flow in the main pipeline $Q_{h}$
$\left[\mathrm{~m}^{3} \cdot \mathrm{s}^{-1}\right]$
4,6
6,4
13,4
15,6
20,2

Table 2. Air flow in the main pipeline depending on the operating mode This must be done due to the need to know the total length of the pipe and its pressure drop. According to the method of total pressures, the piping was designed. The total pressure loss (e.g. see Tab. 3) must not exceed the maximum allowable:

$$
\Delta \mathrm{p}_{\mathrm{z}, \mathrm{dov}}>\Delta \mathrm{p}_{\mathrm{z}, \max }
$$

\section{Operation mode}

\begin{tabular}{|l|}
\hline 1 \\
\hline 2 \\
\hline 3 \\
\hline 4 \\
\hline 5
\end{tabular}

\section{Total pressure loss $\Delta \mathrm{p}_{z}[\mathrm{~Pa}]$}

\begin{tabular}{|c|}
\hline 46,776 \\
\hline 47,076 \\
\hline 49,024 \\
\hline 50,881 \\
\hline 52,034 \\
\hline
\end{tabular}

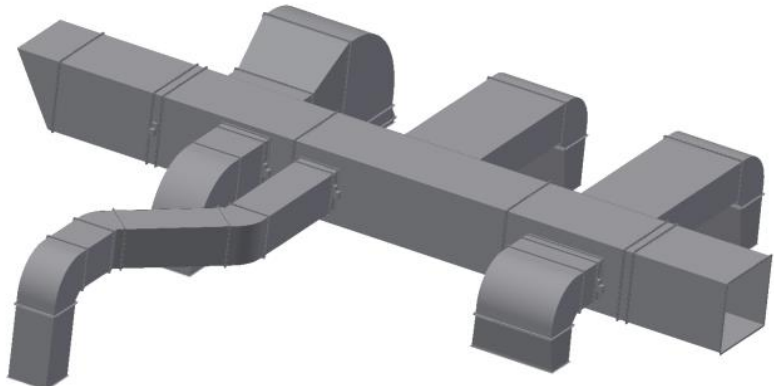

Figure 3. Designed model of manifold

The permissible pressure drop for the operating mode of the compressor station is $\mathrm{Rh}=1.5 \mathrm{~Pa} \cdot \mathrm{m}-1$. With the designed manifold length $\mathrm{lc}=44.6 \mathrm{~m}$, the permissible pressure drop is given by the following formula:

$$
\Delta \mathrm{p}_{\mathrm{z}, \mathrm{dov}}=\mathrm{R}_{\mathrm{h}} \cdot \mathrm{l}_{\mathrm{c}} \quad[\mathrm{Pa}]
$$

The validity of this condition also applies to other pipes, that is outdoor pipes and pipes in a heated building. Subsequently, the pipeline was designed, modeled and production documentation was created as needed. It is advisable to choose the pipeline so that it has, if possible, multiple uses. E.g. in the local conditions of the plant, the air will also be able to be used to preheat the adjacent shaft furnace.

Table 3. Total pressure loss in the manifold pipeline

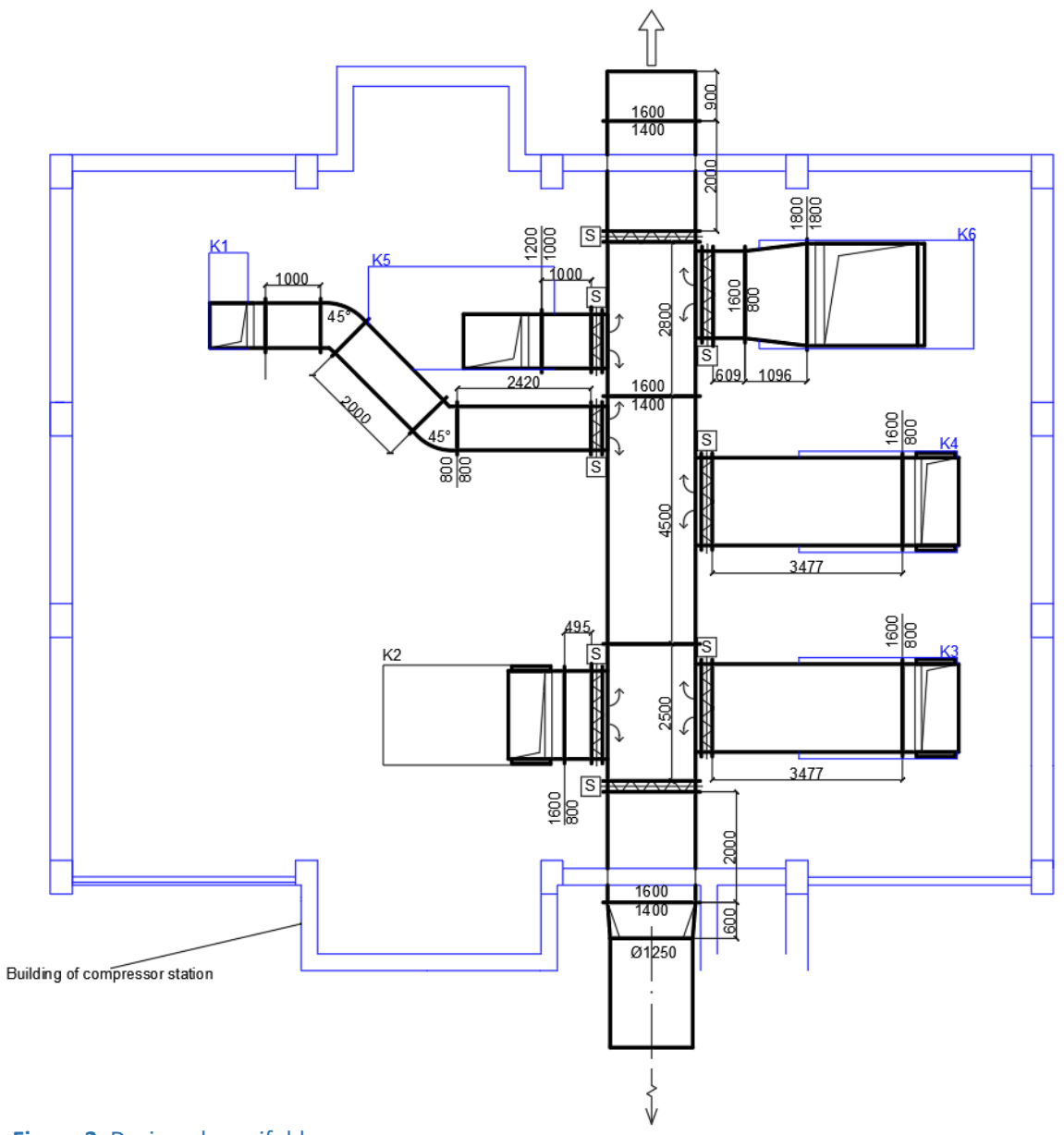

Figure 2. Designed manifold 


\section{WASTE HEAT UTILIZATION}

To use the heat that is removed by air coolers from the compressors, two possible uses have been proposed. The first option is the direct transport of air by hot air duct from the compressor room to the adjacent workshop. As part of this use of heat, the pipeline itself was designed, which will be connected to the designed manifold in the compressor room. It also decided on the possibility of adding a fan to the piping. The second way of using heat is based on the exchangers located at each compressor individually. These will preheat the water for subsequent reheating in the DHW heaters.

For heating and use in the exchanger, a variable heat output will be available, according to the following formula, where the air flow $Q h, v$ is set in $\left[\mathrm{m}^{3} \cdot \mathrm{s}^{-1}\right]$ :

$$
Q_{t}=Q_{h, v} \cdot c_{v z} \cdot\left(t_{2}-t_{1}\right) \quad[k W]
$$

where:

$\mathrm{c}_{\mathrm{vz}}$ - specific heat capacity of air for $\mathrm{t}=40{ }^{\circ} \mathrm{C}, \mathrm{c}_{\mathrm{vz}}=1013 \mathrm{~J} \cdot \mathrm{kg}^{-1} \cdot \mathrm{K}$ $1=1297 \mathrm{~J} \cdot \mathrm{m}^{-3} \cdot \mathrm{K}^{-1}$,

$\mathbf{t}_{1}$ - inlet air temperature in the compressor suction (average value), $\mathrm{t}_{1}=15^{\circ} \mathrm{C}$

$\mathbf{t}_{\mathbf{2}}$ - outlet air temperature at the outlet of the radiator (average value given by the manufacturer), $\mathrm{t}_{2}=40^{\circ} \mathrm{C}$.

According to the local operating modes, the usable heat output is as follows:

\begin{tabular}{|c|c|}
\hline Operation mode & Heat output $\mathbf{Q}_{\mathbf{t}}[\mathbf{k W}]$ \\
\hline $\mathbf{1}$ & 116,49 \\
\hline $\mathbf{2}$ & 162,08 \\
\hline $\mathbf{3}$ & 338,79 \\
\hline $\mathbf{4}$ & 395,07 \\
\hline $\mathbf{5}$ & 511,57 \\
\hline
\end{tabular}

Table 4. Heat outputs in different operating modes

\subsection{Direct transport of hot air - hot air heating}

When designing, it is necessary to pay attention to the pressure and heat losses of the pipeline. In case of excessive pressure drop, it will be necessary to install a fan in the pipe to increase the draft in the pipe. The air is therefore used for direct heating of the workshop by means of a ventilation system. Temperature-controlled dampers are used to ensure the required temperature. In the summer, when it is not necessary to fully use the warm air for heating, the air will be blown out. It was also necessary to verify whether the given amount of blown air will be enough to heat the given premises. This was determined according to the following relationship:

$$
Q_{v t}=1.0 \quad\left[m^{3} \cdot h^{-1}\right]
$$

where:

$\mathbf{Q}_{\mathrm{vt}}$ - required air volume flow $\left[\mathrm{m}^{3} \cdot \mathrm{h}^{-1}\right]$,

I- air exchange rate $\left[\mathrm{h}^{-1}\right]$,

$\mathbf{0}$-volume of space $\left[\mathrm{m}^{3}\right]$.

It was also necessary to find out whether the pressure loss in the whole pipeline is not too great. This was found out from the already mentioned condition. In that case, it was necessary to choose a fan at the end of the outdoor piping (start-exit from $\mathrm{KS}$, end-entrance to the building). Finally, the thermal insulation of the piping had to be designed so that the temperature of the transported air did not fall below a certain temperature. It was chosen according to the thermal calculation from several offered insulations from the company Isover and its thickness was chosen $40 \mathrm{~mm}$ for the collecting pipes in the interior. For outdoor piping, several calculations were performed for different insulation thicknesses (input parameters Tab. 5, comparison Tab. 6). To ensure the best possible thermal insulation, a thickness of $80 \mathrm{~mm}$ was chosen.

\begin{tabular}{|c|c|}
\hline Pipe length & $70 \mathrm{~m}$ \\
\hline $\begin{array}{c}\text { Pipe diameter } \\
\text { Air temperature inside the } \\
\text { pipe }\end{array}$ & $1,2 \mathrm{~m}$ \\
\hline $\begin{array}{c}\text { Coefficient of thermal } \\
\text { conductivity of pipes }\end{array}$ & $40{ }^{\circ} \mathrm{C}$ \\
\hline $\begin{array}{c}\text { Coefficient of thermal } \\
\text { conductivity of insulation }\end{array}$ & $0,035 \mathrm{~W} \cdot \mathrm{m}^{-1} \cdot \mathrm{K}^{-1}$ \\
\hline \begin{tabular}{c} 
Insulation thickness \\
\hline Ambient temperature
\end{tabular} & $0,4,0,6,0,8,1 \mathrm{~m}$ \\
\hline $\begin{array}{c}\text { Surface insulation } \\
\text { temperature }\end{array}$ & $-15^{\circ} \mathrm{C}$ \\
\hline $\begin{array}{c}\text { Ambient wind }(\rightarrow \text { forced } \\
\text { convection) }\end{array}$ & $-9{ }^{\circ} \mathrm{C}$ \\
\hline
\end{tabular}

Table 5. Input calculation values

\begin{tabular}{|c|c|c|c|c|}
\hline $\begin{array}{c}\text { Insulation } \\
\text { thickness [m] }\end{array}$ & $\mathbf{0 , 4}$ & $\mathbf{0 , 6}$ & $\mathbf{0 , 8}$ & $\mathbf{1}$ \\
\hline $\begin{array}{c}\text { Heat loss per } \\
\mathbf{1} \text { m of pipe } \\
\text { [W] }\end{array}$ & 187,41 & 126,90 & 96,63 & 78,46 \\
\hline $\begin{array}{c}\text { Total heat } \\
\text { loss [W] }\end{array}$ & 13111,66 & 8883,19 & 6764,45 & 5492,41 \\
\hline $\begin{array}{c}\text { Medium } \\
\text { temperature } \\
\text { at the end of } \\
\text { the pipe [을 }\end{array}$ & 34,72 & 36,43 & 37,28 & 37,79 \\
\hline
\end{tabular}

Table 6. Resulting values

The exhaust air temperature in the target exhalation should not be higher by more than $20-25{ }^{\circ} \mathrm{C}$ than the desired room temperature ( $\mathrm{min}$. The required room temperature is $15^{\circ} \mathrm{C}$ ). With regard to the price, $80 \mathrm{~mm}$ thick insulation was chosen.

\subsection{Use of air-water exchanger}

This method of waste heat recovery assumed the location of a central heat exchanger or the individual arrangement of the heat exchangers to the individual compressors. The air that is concentrated according to the designed pipeline is driven by an exchanger or exchangers. The exchanger/s preheat the water to the expected temperature of $30{ }^{\circ} \mathrm{C}$. This preheating should then have resulting in a reduction of the energy required for reheating at the place of use itself, because the temperature difference will be reduced (DHW heating in the gas heater). A tubular recuperation countercurrent exchanger is commonly used for the specified conditions. The required heat transfer area was calculated according to the following formula:

$$
\mathrm{Q}_{\mathrm{t}}=\mathrm{k} \cdot \mathrm{S} \cdot \Delta \mathrm{t}_{\mathrm{str}} \rightarrow \mathrm{S}=\mathrm{Q}_{\mathrm{t}} /\left(\mathrm{k} \cdot \Delta \mathrm{t}_{\mathrm{str}}\right) \quad\left[\mathrm{m}^{2}\right]
$$

where:

$\mathbf{Q}_{\mathbf{t}}$ - heat output [kW],

$\mathbf{k}$ - heat transfer coefficient from air to water $\left[\mathrm{W} \cdot \mathrm{m}^{-2} \cdot \mathrm{K}^{-1}\right]$,

$\Delta \mathbf{t}_{\text {stř }}-$ logarithmic temperature gradient of the exchanger $\left[{ }^{\circ} \mathrm{C}\right]$. 
It is understandable that it is not possible to choose an exchanger that can cover all modes of operation and is advantageous both in terms of technology and in terms of costs. Therefore, it will be best to choose the heat exchanger for each compressor separately. I choose a Vosmik E\&C exchanger type GL (Figure 7.13). The company's production program includes these tubular heat exchangers with heat exchange fins, which are adapted for direct connection to rectangular pipes. For the $\mathrm{K} 1$ compressor this will be done by reducing to $0,5 \times 0,5 \mathrm{~m}$ and for other compressors $0,8 \times 0,8 \mathrm{~m}$. The air flow rate in the exchanger used in the calculations is based on these dimensions, see Table 7 .

\begin{tabular}{|c|c|c|}
\hline & \multicolumn{2}{|c|}{ Compressors } \\
\hline Air flow & $\mathrm{K} 1$ & $\mathrm{~K} 2-\mathrm{K} 6$ \\
\hline $\begin{array}{c}\text { Coefficient of thermal } \\
\text { conductivity of pipes }\end{array}$ & $1,8 \mathrm{~m}^{3} \cdot \mathrm{s}^{-1}$ & $4,6 \mathrm{~m}^{3} \cdot \mathrm{s}^{-1}$ \\
\hline \multicolumn{2}{|c|}{ Exchanger (according to the catalog) } \\
\hline $\begin{array}{c}\text { Inner diameter of the } \\
\text { pipe }\end{array}$ & $0,0209 \mathrm{~mW}$ \\
\hline $\begin{array}{c}\text { Outer diameter of pip } \\
\text { Thermal conductivity } \\
\text { of the wall }\end{array}$ & $0,0219 \mathrm{~m}$ \\
\hline Water flow & $308 \mathrm{~W} \cdot \mathrm{m}^{-1} \cdot \mathrm{K}^{-1}$ \\
\hline Water flow rate & $1,5 \mathrm{~m} \cdot \mathrm{m}^{3} \cdot \mathrm{s}^{-1}$ \\
\hline
\end{tabular}

Table 7. Input calculation values

\begin{tabular}{|c|c|c|}
\hline & \multicolumn{2}{|c|}{ Compressors } \\
\hline & $\mathrm{K} 1$ & $\mathrm{~K} 2-\mathrm{K} 6$ \\
\hline $\begin{array}{c}\text { Heat transfer } \\
\text { coefficient }\end{array}$ & $7,68 \mathrm{~W} \cdot \mathrm{m}^{-2} \cdot \mathrm{K}^{-1}$ & $7,66 \mathrm{~W} \cdot \mathrm{m}^{-2} \cdot \mathrm{K}^{-1}$ \\
\hline $\begin{array}{c}\text { Size of heat exchange } \\
\text { area }\end{array}$ & $823,33 \mathrm{~m}^{2}$ & $2109,23 \mathrm{~m}^{2}$ \\
\hline
\end{tabular}

Table 8. Resulting values

After the calculations, the individual arrangement of the exchangers was chosen, that is for each compressor separately and the documentation of the location of the exchangers was prepared

\section{CONCLUSION}

The economic evaluation of the proposal is an important indicator. A new proposal should always be more advantageous than the existing solution. Since my design uses waste air, which is almost free, an early return on investment can be expected. However, the cost of existing solutions must first be determined. However, it should also be noted that the overall evaluation of the project would be much more demanding, as the evaluation would include many other inputs, such as landscaping, mechanization, etc. This is therefore an economic evaluation purely in terms of components designed and as the main output. will be a comparison of the annual costs and the subsequent payback period of the proposal. For the design of hot air heating, the total purchase price was set at CZK 962,977 (EUR 37,656) and the annual operating costs are CZK 43,831 (EUR 1,713). The difference between the annual operating costs is CZK 380,138 (EUR 14,864). The annual profit as a result of the investment is therefore CZK 380,138 and the annual costs decreased by approx. $90 \%$.

For the design with heat exchangers, the purchase price is lower, namely CZK 224,082 (EUR 8,765). The annual operating costs are then CZK 150,190 (EUR 5,874). According to the operating rules of space heating, DHW heating is solved by a separate gas heater. The boiler heats the water to a temperature of $60{ }^{\circ} \mathrm{C}$. By supplying water with a higher temperature (ie $30{ }^{\circ} \mathrm{C}$ ) than normally heated water, the operating costs of the boiler can be reduced by approximately $30 \%$. The operation of this boiler burdens the company with the amount of CZK 179,964 (EUR 7,037) per year. The annual profit as a result of the investment is therefore CZK 29,774 (EUR 1,164) and the annual costs decreased by approx. $16.5 \%$.

This was only an example of the use of heat exchangers together with a boiler for DHW heating. This principle of heat utilization could be applied to any boiler. The same applies to the use of waste heat for hot air heating. Even other possible uses cannot be neglected. This is a modern trend that is under increasing pressure. Many companies try to reduce costs where possible, but many neglect this option. The presented article therefore shows an example of reducing operating costs and according to the achieved results, it can be concluded that the investment would not be in vain. 


\section{REFERENCES}

[AC 2019] Atlas Copco, Compressed air manual [online]. 2019 [20.4.2021].

Available from https://www.atlascopco.com/content/dam/atla s-copco/local-countries/netherlands/documents/compressedair-manual-8th-edition.pdf

[Balas 2019] Balas, M. Boilers and heat exchangers. Third edition. Brno, Academic publishing house CERM, 2019. ISBN 80902689-3-5

[Balek 2005] Balek, S. Thermal technical tables and diagrams. Second edition. Ostrava, VSB-Technical University of Ostrava, 2005. ISBN 80-248-0828-5

[Cuhra 2004] Cuhra, J. Waste heat capture by air-water exchanger. VVI, January 2004, Vol.1, No.1, pp 32

[Dvorak 1983] Dvorak, Z. Heat exchangers (for hydraulic and pneumatic machines). Prague, Czech technical university in Prague, 1983

[Chysky 1993] Chysky, J. and Hemzal, K. Ventilation and air conditioning. Third edition. Brno, BOLIT-B Press, 1993. ISBN 80901574-0-8

[Isover 2020] Isover Saint-Gobain, Orstech 65 [online]. 2020 [20.4.2021]. Available from https://www.isover.cz/produkty/orstech-65

[Kaminsky 2004] Kaminsky, J., Kolarcik, K. and Pumprla, O. Compressors. Ostrava, VSB-Technical University of Ostrava, 2004. ISBN 80-248-0704-1

[Kolarcik 2004] Kolarcik, K. and Vrtek, M. Possibilities of energy savings in the production, distribution and consumption of compressed air. Prague, OPET, 2002. ISBN 80-902689-3-5

[Lindab1 2020] Lindab, Air duct systems [online]. 2020 [20.4.2021]. Available from

http://www.lindab.com/cz/Documents/Ventilace/katalogy/_AD S_produkty/katalog_ADS_potrubni_systemy.pdf

[Lindab2 2020] Lindab, Ventilation price lists [online]. 2020 [20.4.2021]. Available from http://www.lindab.com/cz/pro/software/dokumentypdf/dokumenty-ventilace/ceniky/pages/default.aspx

[Mauer 2007] Mauer, K. Ventilation equipment. Third edition. Prague, Sobotales, 2007. ISBN 978-80-86817-21-7

[TZBinfo1 2020] TZBinfo, Elements of ventilation and air conditioning equipment [online]. 2020 [20.4.2021]. Available from https://vetrani.tzbinfo.cz/vzduchotechnicka-zarizeni/3769-prvky-vetracich-aklimatizacnich-zarizeni-i-2-cast

[TZBinfo2 2020] TZBinfo, Calculation of hot water heating time [online]. 2020 [20.4.2021]. Available from https://vytapeni.tzbinfo.cz/tabulky-a-vypocty/97-vypocet-doby-ohrevu-teple-vody

[TZBinfo3 2020] TZBinfo, Fuel and energy prices [online]. 2020 [20.4.2021]. Available from https://www.tzb-info.cz/ceny-paliva-energii

[TZBinfo3 2020] TZBinfo, Calculation tool ECONOMIC EFFICIENCY OF INVESTMENTS [online]. 2020 [20.4.2021]. Available from https://stavba.tzb-info.cz/2786vypoctova-pomucka-ekonomicka-efektivnost-investic-ii

\section{CONTACTS:}

Ing. Lukas Pacas

VSB - Technical university Ostrava

Faculty of Mechanical Engineering

Department of Machine and Industrial Design

17. listopadu 2172/15, Ostrava, 70800 , Czech republic

Tel.: +420 596994452

Email: lukas.pacas.st@vsb.cz 